\title{
Learning How: Reflexive Body Techniques, Skill Acquisition, and the Consumption of Experience
}

\begin{abstract}
Although the skilful body has been ever-present in research accounts of consumption experiences, no sustained attention has been given to the acquisition of skills necessary for successful engagement with those experiences. In the present study, we report an empirical investigation of the acquisition and diffusion of embodied competencies amongst high-speed motorcyclists. In doing so, we mobilise the concept of reflexive body techniques in order to unpack the social, physical and mindful aspects of skilled embodiment. We demonstrate that skill acquisition is a necessary precursor to successful immersion into certain kinds of consumption experiences offered by the marketplace. Further, we underline the role of skill acquisition in subject formation.
\end{abstract}

\section{Keywords}

Skill acquisition, body techniques, embodiment, body, habitus, experience, phenomenology, perception, motorcycling, observant participation. 


\section{Learning How: Reflexive Body Techniques, Skill Acquisition, and the Consumption of Experience}

\section{Introduction}

Initially offered as part of an oppositional reading within a consumer research discourse centred on rational, utility seeking consumers (Holbrook and Hirschman, 1982), terms such as 'consumer experience' and 'experiential consumption' have become ubiquitous (Holbrook, 2001; Carù and Cova, 2003). Indeed, the experiential approach has been employed to illuminate consumer engagement with a range of extraordinary (Arnould and Price, 1993), fantastical (Belk and Costa, 1998) and emancipatory encounters (Kozinets, 2002). Often, set against the backdrop of postindustrial disenchantment, this perspective documents the struggle to invigorate everyday life with excitement, forging communitas (Celsi et al., 1993) and transcending standard societal structures (Kozinets, 2002).

Despite its obvious contribution, the literature on experience has been criticised for a lack of definitional clarity (Carù and Cova, 2003) and a reliance on a limited theoretical palette (Lanier and Rader, 2015). Within social science and philosophy the term 'experience' is "defined as a subjective episode in the construction/transformation of the individual" (Carù and Cova, 2001: 273) and in this reading all experiences become consumer experiences (Woodward and Holbrook, 2013). The transformation of the individual is predicated upon the idea that experiences are not just otherdirected, but are also focused inwardly towards the development of inner pleasure (Jantzen et al., 2012). For Lanier and Rader (2015: 4), the theoretical assumptions that underpin this perspective compel researchers to assume that "consumption experiences have identifiable and interpretable consequences ... and that these consequences (functions) are often linked to the intentions (i.e. aims and motives) of those involved". In this way, scholars have focused largely on the functional aspects of experience and, thus, Lanier and Rader (2015) advocate consideration of a range of experiences from functional to anti-functional and from structural to anti-structural. Moreover, 
almost completely absent from this body of research is any focused treatment of skill acquisition. It is to skills that this paper turns, illuminating the activities that precede and surround experience. While the development of expert skills is not a necessary precondition for engaging in experience (Beauchez, 2018), proficiency becomes important during high-risk leisure where lives are on the line (Arnould and Price, 1993; Celsi et al, 1993; Murphy and Patterson, 2011), where efficacy is a key motivation for engagement (Arnould and Price 1993; Celsi et al., 1993), and where the possession and development of 'capital' within the community is of concern (Kane and Zink, 2004).

In laying the foundations for the experiential perspective, Holbrook and Hirschman (1982) recognise that experience is first and foremost grounded in the body and emphasise the immediacy of embodied experience as it is lived. It might be reasonable to expect, then, that lived embodiment might have garnered greater attention within consumer research. However, consideration of the body remains limited largely to theories of corporeal inscription (Grosz, 1994) rather than opening up to a lived body that "consists essentially in processes of self-productive activity, at once subjective and objective, meaningful and material, personal and social, an agent that produces discourses as well as receiving them." (Turner, 1994: 46). Ultimately, then, comprehensive accounts of the embodiment of action remain relatively elusive (Joy and Sherry, 2003).

A corpus of research on the embodiment of experiences has begun to establish itself. Goulding et al. (2009) address the biosocial dimensions of pleasurable experience within the energised context of clubbing. They find clubbers losing themselves in an "orgy of sensation seeking experiences" (p. 266), whereby standard protocols regarding touch, sound, light and communication are vividly exceeded. Turning attention to the performative aspects of experience, Hewer and Hamilton (2010) identify how dancers feel a fleeting sense of liberation when their bodies move spontaneously and innovate around the rules of the dance. Concerning the nature of sleeping, Valtonen and Närvänen 
(2015) conceptualise a body that is at once biological and cultural, a body that learns to adopt a range of techniques that ensure that people get to sleep in culturally appropriate ways. Meanwhile, Woermann and Rokka (2015) offer a novel means of thinking about the temporality of experiences, describing how the slowing down of perceived time occurs as a result of finely tuned bodily routines that enable consumers to improvise actions in the moment. Precognitive bodily functions, such as breathing and heartbeat, are strongly implicated in the timeflow of extraordinary consumption experiences. Because these precognitive functions are affected through practical performance, they simultaneously shape the actions of consumers and perceptions of the experience. Further, Scott et al. (2017) highlight the significance of the embodied experience of pain in the gruelling obstacle race Tough Mudder. Pain induced by the event demands the immediate attention of the runner to the extent that usual thought processes are pushed to background. For immobile white collar workers, this painful leisure pursuit allows them to reconnect with their bodies, affording them moments of escape from an otherwise saturated self. In terms of skill development, Seregina and Weijo (2016) allude to the competencies necessary for engagement in Cosplay culture and suggest that such skills (sewing, make-up artistry etc.) contribute to the gendered nature of the community. More fundamentally, Thompson and Üstuner (2015) deploy Bourdieusian analysis to understand the transformations in embodiment and gendered habitus undertaken by women within roller derby. These transformations involve the acquisition of new skill sets, and training the body such that it becomes stronger, more agile, more resilient and thus more suited to playing the sport.

This stream of research convincingly establishes that accounts of embodied experience need not be divorced from the purpose, meaning, goals and norms that emerge as a result of consumers' marketmediated experiences. By addressing the performative aspects of experience, this work uncovers a skilful body that emerges as an outcome of culturally specific ways of learning. Mobilising the concept of body techniques (Mauss 1973) our focus here is oriented towards the social, physical 
and mindful aspects of learning as they relate to culturally specific modes of bodily movement. Posing the question how do consumers gain the necessary skills to engage in experience, our study examines the acquisition of body techniques within the context of high-speed motorcycling.

While motorcycling has provided the backdrop for some seminal consumer research work (e.g. Schouten and McAlexander, 1995; Martin et al., 2006) it was Haigh and Crowther (2005) who moved attention away from the meanings surrounding motorcycling culture to concentrate on the activity of motorcycling itself. Haigh and Crowther (2005) look beyond the outlaw mythos, drawing attention to the growing popularity of performance styles of motorcycling in Britain, evidenced by the dominance of super-sport styles of motorcycles in the UK market (Haigh and Crowther 2005). They frame motorcycling as high-risk leisure and illustrate the fluidity of attitudes held by motorcyclists toward risk. By studying riders at different stages of their career, Haigh and Crowther (2005: 556) demonstrate how experienced riders evolve from an understanding of motorcycling rooted in "excitement, performance, and speed" to a more sensible approach focused on "competence, wisdom and safety." Murphy and Patterson (2011) expand further by exploring attempts by riders to manage the risk involved in high-speed motorcycling. They question why people continue to engage in high-speed motorcycling in light of associated accident statistics. Highlighting the autotelic qualities of motorcycling, the behaviour is framed as an experiential practice rooted in "intrinsic motivation, enjoyment, and pleasure" (Murphy and Patterson 2011: 1329).

Recent accounts of motorcycling, then, underline the sensuous and embodied nature of the experience. Whether motorcycling is predicated upon sensual appreciation (Martin et al., 2006), managing risk (Haigh and Crowther, 2005), or maintaining control in chaotic situations (Murphy and Patterson, 2011), skill acquisition remains a key precursor for those seeking these experiences. Nonetheless, little is known about the development of competencies that enable motorcyclists to 
successfully negotiate these experiences. Focusing explicitly upon the acquisition, habituation and diffusion of body techniques among high-speed motorcyclists our research directly addresses this dearth of understanding.

Next we introduce Nick Crossley's work on embodiment, outlining a phenomenological understanding of perception to extend the concept of body techniques offered by Mauss (1973). Crossley demonstrates how body techniques provide a useful heuristic for examining skill acquisition. Following this we offer a detailed description of the observant participation (Wacquant, 2004) and Biographic Narrative Interpretive Method (Wengraf, 2001) employed in our investigation. Finally, we present our findings as they relate to the novice's path of development and habituating bodies, and lay out a set of contributions developed in relation to the social, physical and mental aspects of body techniques.

\section{Conceptualising Embodiment}

Crossley's work on embodiment in (inter)action (2001, 2004, 2005, 2007), is part of an important strand of sociological research that moves beyond "representations of and discourses on the body, beyond things done and attached to the body, to explore embodied agency and practice" (Crossley, 2007: 80). In turning attention to practices that constitute the body (Wacquant, 1995a; 1995b), this work demonstrates how the constituting practices of a given social world can "invest, shape and deploy" (Wacquant 1995a: 65) the human body to such an extent that social structures become embodied. Crossley (2007: 82) reinstates the embodied experience of daily life, reminding us that we are our bodies, and that all of our interactions assume an embodied form:

Our embodiment ... locates us in the world, putting us in a spatio-temporal relation with other beings and giving us a standpoint, literally, from which to perceive them. Our embodiment is also the basis of our consciousness, however. My body ... has another 'inside' that surgeons and neuroscientists cannot access; an inside comprising lived sensations which form the coherent and meaningful gestalt structures that are my consciousness of the world ... Phenomenology alerts us to the body's own, inside out perspective, and thus to the body of the observer. 
From this phenomenological account of embodiment, we can appreciate that we do not perceive our own sensations. We have sensations but perceive a world beyond ourselves. If we are to see we must have a visual sensation, but it is the world around us that we perceive rather than perceiving that visual sensation. The body actually becomes absent through the process of embodiment. Although all experiences are embodied, they are not all experiences of the body (Crossley, 2007). Similarly, the body also becomes absent in action that involves movement (Leder, 1990). Crossley (2007: 83) uses the "purposive, intelligent and cultured movement" of typing to illustrate that, for the competent typist, this action can be achieved without conscious awareness of the body or even cognitive appreciation of the keyboard layout.

Merleau-Ponty (1962) unpacks perceptual focus, demonstrating that the foregrounding of a particular experience always occurs at the expense of others. Awareness of our own embodiment is most apparent in experiences that foreground the body's dysfunctions, such as sickness or pain (see Scott et al., 2017). Such experiences jolt perceptions of the body to the foreground, while perceptions of the world simultaneously recede to the background. Their dysfunctional nature highlights the requirement for bodily absence in daily life. Merleau-Ponty (1962) extends this line of reasoning to social experiences, arguing that at the heart of "intersubjectivity and thus the social world is a 'chiasmic' intertwining of bodies: perceiving and perceptible, sensuous and sensible" (Crossley, 2007: 84). While embodiment has proved a difficult theoretical concept to utilise in empirical analysis (Andersson et al. 2015), Crossley's research demonstrates that it is possible to investigate the meanings, goals, norms and rules of social worlds, without losing touch with the body. 


\section{Extending a phenomenological account of body techniques}

Body techniques capture the "ways in which from society to society men (sic) know how to use their bodies" (Mauss, 1973: 70). They call attention to the social dynamics of learning as they relate to culturally specific modes of bodily movement (Morris, 2004). Their essence is captured by Mauss (1973: 72) on his experience of a stay in hospital:

I wondered where previously I had seen girls walking as my nurses walked. I had the time to think about it. At last I realised that it was at the cinema. Returning to France I noticed how common this gait was, especially in Paris; the girls were French and they too were walking in this way. In fact, American walking fashions had begun to arrive over here, thanks to the cinema. This was an idea I could generalise.

Bodily movements do not have a 'natural' form. Even the most taken-for-granted modes of embodied action are shaped by socio-cultural relations (Morris, 2004). The fact that French girls walk differently indicates that body techniques are neither hardwired nor individually idiosyncratic. Individuals learn to embody techniques that are, in the first instance, foreign to them. They exist in any one moment-in-time through individual performance, but importantly they also exist before and after individual performance. The structured nature of body techniques restricts but does not remove an individual's capacity for inventive action. The biological aspects of body techniques, reveals the "innate intelligence, sociability and plasticity that enables us to invent, teach and learn specific techniques" (Crossley, 2007: 85). But the capacity to use our bodies also reinstates the fact of our bodily form. Anatomical structures enable and constrain the human potential for action. Body techniques also have a mindful dimension in that they are embedded with knowledge and understanding (Crosley, 2007). Learning to swim, for example, requires understanding that extends beyond one's capacity to reproduce particular patterns of bodily movement. Aspiring swimmers must attain a pre-reflective understanding of the principles of buoyancy, propulsion and water displacement. This does not require a cognitive appreciation of the principles of physics. Rather this understanding is grounded in practical know-how, developed not through rational calculation but through an 'embodied feel' (Crossley, 2004). 
Through repeated performance, body techniques sediment into a form of habitual understanding that encompasses particular ways of seeing and responding to the environment. Through their acquisition, agents become (pre)disposed to respond in typical ways to typical situations (Crossley, 2001). To this end Mauss (1973) offers habitus to theorise the collective, practical understanding incorporated in body techniques. Crossley (2001) contends further that we are our habits in so far as our perceptions, thoughts and feelings follow habituated patterns. Yet our capacity for selfreflection provides us with an opportunity to contemplate these habituated patterns, allowing us to make conscious decisions to modify these patterns. In bringing attention to the acquisition of embodied knowledge, and attributing agents with the capacity for self-reflection, Crossley's habitus is markedly distinct from Bourdieu's (1984) use of the concept. While Bourdieu's interest lay in employing the habitus to unpack the nature of class relations, Crossley's application remains focused upon the learning processes involved in (trans)forming bodily dispositions. Crossley (2001) invites researchers to work with the concepts of self-consciousness and reflexivity to explore the ways that agents come to develop and maintain a sense of self, body and habits.

\section{Method}

To research body techniques is to situate knowledge and understanding in the form of embodied know-how. Body techniques highlight the social dynamics of practical knowledge, reminding us that their principles are diffused in networks of interaction. If these principles can be communicated from expert to novice, then they can also be transmitted from expert to a researcher (Crossley, 2007b). Accordingly, the first stage of data collection encompassed periods of 'observant participation' (Wacquant, 2004) consisting of the first author participating in group rides while also engaging in more structured lessons with a qualified motorcycling instructor. The dynamics of these learning encounters intensifies the extent to which the ethnographer becomes "an object of indigenous scrutiny, local pedagogies, and community techniques for transforming less-skilled aspirants into experts" (Downey et al., 2015: 184). Observant participation holds that an embodied 
analysis of action necessitates the acquisition of the specific embodied capacities under investigation. This approach presents an opportunity for the researcher to become immersed in the sensuous flows and rhythms of bodily movement (Larsen, 2014). Observant participation recognises auto-biographical materials as research data and the auto-ethnographic accounts employed in the present study are centred on the first author's experiences of learning to ride a high-speed motorcycle (for similar examples see Sudnow, 1993; Spencer, 2009, 2014; Downey et al., 2015; Beauchez, 2018).

This method is ideal for the study of body techniques. First, the knowledge transmission process illuminates the principles embedded in body techniques. Inhabiting the role of novice, forces the expert to be reflective in terms of finding ways to explicitly communicate these principles, increasing the likelihood of the researcher 'getting it' too. The observant participant's practical ineptitude is oftentimes key to gaining access to the tacit knowledge that participants hold (Downey et al., 2015). Second, a focus on the learning encounter emphasises the technical nature of body techniques that is illustrated when novices encounter the distinction between a cognitive appreciation of how techniques should be performed and actually putting them into action. Third, observant participation is vital not only in terms of building rapport with participants, but also in terms of developing the understanding required to engage with participants in relation to the technical specificity of body techniques.

When it comes to the study of embodied habits, routines, and practices qualitative researchers have tended to privilege participant observation because of its assumed capacity to give direct access to action (Halkier and Jensen, 2011). Atkinson and Coffey (2003) contend that the process of observing action in situ, is just as entangled in social interpretation as any data obtained through interview. Observant participation and interviews can thus equally be conceived as performances of social actors. Nonetheless, to supplement data obtained through observant participation, we adopted 
a biographical narrative interpretive method (BNIM) of interviewing. At regular intervals over a four-year period, we conducted narrative-based interviews with 8 participants (Table 1), with attention focusing on the on-going development of their careers as motorcyclists. As retrospective accounts, these narratives reconstruct "decisions, actions and events" from the past, locating the storyteller in relation to the particular "contexts, situations, relationships and moral judgements pertaining to these" (Phoenix and Brannen, 2014: 14).

Insert Table 1 around here

Arnold and Fischer (1994) and Thompson (1997) establish an epistemological footing for narrative enquiry within consumer research underlining its utility in understanding the ways that consumers' structure their experiences, enabling us to make sense of specific aspects of their lives. Narrative approaches have recently been employed to examine experiential themes such as health activism (Cronin and Hopkinson, 2017) and consumer identity transformation through tourism (Ourahmoune, 2016). BNIM is distinguished from the rich range of general narrative approaches by its focus on action and latent meaning (Chamberlayne and King, 2000). For the purposes of the present study, BNIM provides clear guidance on developing interview strategies directed towards inducing narratives responses that represent participants' practical development as high-speed motorcyclists. The BNIM approach separates the interview process into three distinct sub-sessions. The first session provides participants with space to construct their own personal narrative. The first sub-session opens with a Single Question aimed at Inducing a Narrative response (SQUIN). For example: 'Can you tell me about your life as a motorcyclist?' During this process the researcher's “interventions are kept to a minimum and drained of any particular content, for as long as possible you give up control, refuse to take up offers of partial control and maintain the maximum of power asymmetry against yourself" (Wengraf, 2001: 113). The second sub-session is conducted in a similar way; the interviewer using issues raised in the first sub-session to develop more specific 
Topic Questions aimed at Inducing Narrative (TQUIN). Where necessary, a third sub-session is conducted with questions developed on the basis of the researcher's preliminary analysis of SQUIN and TQUIN.

Coding organised the data-set into manageable categories and facilitated the emergence of key themes (Coffey and Atkinson, 1996). An idiographic approach, was first employed to appreciate field-notes and each of the interviews as a whole in and of themselves. The second phase encompassed a part-to-whole assessment (Thompson et al., 1989), identifying areas of convergence across the data set. These were identified as global themes on the basis that they represented the shared experiences of participants. The third phase organised the data into meaningful categories, connecting representative occurrences of phenomena together on the basis of their shared properties (Coffey and Atkinson, 1996). Procedurally, the process of coding was important in terms of ordering the data into manageable units and enabling localised themes to emerge. As a heuristic device, coding enabled us to think about and interact with the data. The next stage of analysis mobilised interpretation to identify "patterns, themes, regularities as well as contrasts, paradoxes and irregularities" (Delamont, 1992, cited in Coffey and Atkinson, 1996: 47). This established pathways through the data. This iterative process of coding and interpretation helped make sense of the data-set and develop ideas about the most important themes and the linkages between them. While this process is described here in a linear trajectory, in actuality these analytical processes were emerging and developing right throughout the research process. To give representation to the process of skill acquisition, our findings are presented in chronological order, tracing the development of motorcyclists from novice to expert. In the interests of following the novice's path of development, our findings pay particular attention to three core narratives (Leon, Paddy and Eoin). Despite this focus, the data presented in the findings are representative of our emergent themes across the data set. 


\section{The Novice's Path of Development}

I started off with bikes from the age of $8 \ldots$ I had friends that had Honda 50s and we just started in the fields. Every evening we were out driving around ... so eventually I got my own Honda 90. So that's when it started I think ... At the age of 12, I moved onto a 100cc RXS. I was still in the fields and then I was putting all of my money into them ... Then I had a scrambler at one stage ... I think I had six of them. At the start, I think I was attracted to the freedom ... especially the freedom in the field ... we didn't have to wear a helmet or anything. It was just go out and rally the shit out of it in the field. At the start, all of the lads had Honda 50s and I suppose I just wanted something a bit faster.

[Eoin, 28]

Many of the participants began motorcycling before they were legally old enough to do so. Formative experiences occurred well-away from the institutionalised space of the public road; in forests, fields and private roads they experienced motorcycling free from the regulations that normally govern motorcycling. These experiences shaped an understanding rooted in notions of speed, freedom and individual autonomy. Rosa (2010, n.p) explains how "speed in modernity is closely connected to ideas of power and self-determination or autonomy, and hence to the experience of freedom and happiness". The desire for speed may be wrapped up in romanticised notions of 'the good life' that is lived free from regulation and constraint. Through their stories, we learn about the individual activities of participants and the social relationships that underpin their progression from novices to skilled motorcyclists. Eoin reveals his desire for skill development, and competition in pursuit of the high-speed experience. Along this path of development, these novice motorcyclists share a host of experiences that shape their understanding of and engagement in motorcycling:

Before I actually got the first bike I was probably after crashing three or four bikes belonging to my friends - from going fast or showing off or doing whatever I wanted ... When I bought the bike first ... I thought I knew how to drive [it] but then I realised that I wasn't able to drive the bike at all. It took a long time then to actually learn how to drive the bike and gain the skills that you needed to actually have fun on the bike ... I never really found it scary going fast in a straight line but when you are going around a bend fast it actually takes skill.

[Leon, 28] 
Leon positions skill acquisition as an essential prerequisite for those seeking to experience the range of sensations and emotions accessible through the high-speed experience. Experiences cannot always simply be consumed. Technical objects, such as the motorcycle, demand engagement and knowledge, necessitating a set of appropriate skills for their use (Dant, 2004). Novices must invest time and effort if they are to master the range of complex body techniques that are required. On the topic of skill acquisition, Malcom Gladwell (2008) proposes the 10,000 Hour Rule, contending that with this level of investment in training any person can become world-class in any field. A recent meta-analysis of studies on deliberate practice (Macnamara et al., 2014) goes a long way towards debunking Gladwell's rule, evidencing that although practice is a relatively consistent predictor of success in activities where the structures of activity remain stable (such as tennis, chess or classical music), practice is a less reliable predictor of success in activities where the rules of action are less fixed. In this respect, it may be nigh on impossible to generalise when it comes to predicting the investment of time required to learn to play free jazz or even how long it may take an aspiring motorcyclist to acquire the skills to safely negotiate the road at speed. Our aims thus remain rooted in the phenomenological ethos of portraying the lived, embodied experiences of learning in this lifeworld. As we will learn throughout this enquiry, there are many factors outside of the individual's immediate control that shape their development as motorcyclists. The first author began his research journey, as a novice, participating in group motorcycle rides, observing demonstrations, and taking instruction from more experienced high-speed motorcyclists:

Kevin has agreed to come and observe me riding so that he can give me some pointers on how I can improve my technique ... As we leave the city the road starts to clear. I pull the throttle to pick up the pace. The first real bend is a right-hander. I dip a little, searching for the right line, but I press the brakes too early and it kills the bike's speed. Moving through the bend, I'm scrambling to drop a gear, to accelerate, to quickly get out of the bend. After dipping around the bend, I can see that the road in front is clear. I kick through the gears, all the time working between throttle and clutch. A quick glance down and I can see that we are pushing for 130. Approaching a tight left-handed bend, I ease off the throttle; working down through the gears to prepare the bike for negotiating the bend. I shift my weight, the bike dips through the tight bend, but the manoeuvre feels sluggish and laboured. Kevin pulls up beside me and signals to pull in at the lay-by. He gets off the bike and my first lesson in high-speed motorcycling begins... 
The intercorporeal relationship between novice and master is illustrative of the mirroring role of others in surveying body techniques and correcting poor form (Crossley, 2004). Kevin's acquired knowledge, his habitus, can be deployed to shape not only his own actions but also those of others:

Your safety glances are all over the shop. Basically anytime you're moving your bike on the road, left or right, you need to check your mirrors and your blind spots ... There were a couple of times there that you overtook cars and you checked your mirrors but you never checked your blind spots ... The other thing that I noticed was your body position ... [Kevin sits up on my bike and begins to demonstrate] ... When you were coming up to the bend you're sitting straight up on the bike. But really where you want to be is, you want your elbows tucked in, you want to be far down ... [Kevin crouches forward on the saddle, his upper torso almost over the petrol tank, his arms are bent] ... Your arse comes out and you literally hang off the side of the bike. So you're physically putting yourself into the corner. It's all about shifting your weight. It's not just moving the bike on the road. You have to move yourself on the bike. So your bum comes out off the side of the bike and you're tucked right into the corner like this ... [He is almost hanging fully off the bike now] ... The next thing, then, is your positioning on the road ... You need to be thinking of things in terms of visibility. If we take the example of the hairpin bend after the long straight. Coming up that long straight you want to be out on the white line, which is giving you the clearest line of vision on where you're going ... Out on the white line you can see the most. Then, say in terms of a racing-line to get around the corner the quickest, you want to be out on the line for as long as you can. But obviously on nights like this where the road is busy you've got to be careful not to go out onto the other side of the road. You know you've got to acknowledge that we're not on a race track so you can come out as far as the white line but that's definitely it. Let's go again and you can fall in behind and have a look.

[Kevin, 45]

This interaction between novice and expert is centred on high-speed cornering techniques. Kevin's use of his body to illuminate this complex technique is itself a craft honed through years of experience as an instructor. His ability to make gestural use of his body is central to disseminating practical understanding and cultivating learning relationships (Spencer, 2009). While we may commonly refer to the transmission of practical knowledge, the first author's many frustrating attempts at learning these skills highlight that novices will not always be capable of doing exactly as their teachers do - "while training offers opportunities to develop skills; it does not inject an 
unvarying code or implant a uniform body of tacit knowledge in the student" (Downey et al., 2015: 193).

The aim here is to manoeuvre the motorcycle such that it enables the motorcyclist to negotiate corners at the highest speed possible. The physical aspects of body techniques reveal the "innate intelligence, sociability and plasticity that enables us to invent, teach and learn specific techniques" (Crossley 2007: 85). But the capacity to use our bodies also reinstates the fact of our bodily form. Anatomical structures enable and constrain the human potential for action. Moreover, the necessity for learning to manoeuvre the body to maximise vision illustrates that structures of perception are not simply conditioned by the body, but rather perception is constituted by the structures of the body (Carman, 2008). On this basis, we posit that the perceptual horizons of the motorcyclist experience must be recognised as functions of the body in which they are realised.

Kevin's use of the term 'racing-line' invokes a shared understanding of how body and motorcycle should be moved. It illustrates how the expert's demonstrations and corrective instructions can be employed to shape the novice's efforts at imitating this body-technique, while also showing how pedagogic mechanisms can impose a cultural form upon the novice's emerging understanding (Downey et al., 2015). Skill acquisition takes place within a normative context with a structuring effect upon body techniques, ensuring here that the novice learns to move in line with shared understandings of how this technique should be performed. Within all groups, there is a correct way of performing body techniques and novices are expected to conform to these norms (Dreyfus, 2014). Kevin is unequivocal in the understanding that 'safety glances' must be performed to ensure that 'blind spots' are seen prior to any movement of the motorcycle. Through his instruction, Kevin ensures that this pre-existing knowledge continues to proliferate among novices. Thus, we can appreciate that although body techniques "only exist insofar as agents practice them ... they nevertheless pre-exist individual agents and will outlive them" (Crossley, 2004: 38). The correct 
way of performing high-speed motorcycling techniques is itself a social construction, formed on the basis of the existing knowledge of motorcyclists and the structurally determined rules of the road. Varying expectations regarding the correct way are disseminated in rule books, formal training courses, informal conversations and on social networks (Murphy and Patterson, 2011). While on a surface level, the learning encounter may appear to be dyadic, intersubjective exchanges of this nature are in fact always drawing upon and contributing to the broader network of knowledge (Mauss, 1973). Through processes of habituation, this knowledge comes to causally underlie the high-speed motorcyclist's perceptual orientation in the world. What is perhaps less obvious is that these capacities and dispositions establish the normative dimensions that underlie the intentionality of the motorcyclist's perception. It is these norms that contribute to "the felt rightness and wrongness of the various bodily attitudes that we unthinkingly assume and maintain through our waking (and sleeping) lives" (Carman, 2008: 110).

Leon's account of learning to master the 'wheelie' exemplifies the novice's capacity to mindfully reflect upon their own practical sense, for the teleological purpose of shaping their personal transformation (Noble and Watkins, 2003). His recollections emphasise the physical nature of body techniques encompassed by forms of practical reason:

I remember before I got the bike watching Luke do it. Watching what he was doing with his legs and his hands. So before I even had the bike, I was practising by doing it in my head. In my head ... I'd leave out the clutch and open the throttle and I'd be doing all these different things ... I asked people as well. I think I used to be even asking people if I could try it out on their bikes. I just wanted to learn how to do it and ... yeah ... Luke told me how to do things. But someone telling you how to do it wasn't enough and then I'd get on the bike and I'd try do it but that wasn't enough. You had to practice it yourself and really get a feel for it. From between when Luke told me how to do it and when I actually really started to do it, it must have been months before I could actually do it myself ... it was just practice, practice, practice. If you were trying to do a wheelie, it was just driving along in first gear and trying to get the combination of things right ... keep doing it over and over again until you have it.

[Leon, 28]

Leon illustrates the important distinction between conceptual knowledge and practical bodily knowhow. Recognising the limitations of observation and instruction in learning to perform this body 
technique, he realises that to truly know this technique he has to be able to do it (Crossley, 2004). In the beginning, the novice does not possess a feel for high-speed motorcycling techniques. As Leon suggests, the feel for body techniques can never be fully transmitted to the novice by more skilful riders. The process of becoming a high-speed motorcyclist requires more than cognition. Embodied transformation necessitates repetitive action, referred to here as 'practice'. To 'get a feel for it', is to know without thinking the weight of the motorcycle relative to the engine's power, the moment when the clutch should be released in order to generate enough power for the front wheel to rise in a controlled manner, and how the body should be positioned in order to maintain balance. Understanding of this nature cannot be reached through 'reflective calculation'. Rather it is an "embodied feel, a practical sense of self and world derived from immersion in practice" (Crossley, 2004: 49). In developing this feel, proficient high-speed motorcyclists are afforded a correct and proper view of their world: that "feel is neither the buzz and hum of sensation nor the rationality of deliberate thought" (Carman, 2008: 111). For a wheelie to be performed successfully, the rider must instantly draw this understanding together as a whole - in the moment there can be no time for reflection. Paddy further evidences the role of repetition in the acquisition of body techniques:

I was trying to get my knee down for ages on the 250 . But I could never do it! There was one big roundabout out near Granagh castle. It was a big huge massive one. I'd been driving twisty roads so I knew I had the heat in the tyres. So you'd have the confidence to kind of try ... I wasn't even looking at my speed or anything and I just fucked it into the roundabout. When you're trying to get your knee down the guidelines say that you should have one arse cheek, if not even one and a half arse cheeks off. Underneath, your toe should be on the peg and ... you stick your knee out. Next thing, all I could hear was this screeeech. It took a split second and then I was like ... I got my knee down! I finally got my knee down! ... I just had a childish burst of excitement inside the helmet and I was roaring and shouting ... I was finally after doing it and it wasn't that I was trying so hard but I had been trying and trying to do it and I could never do it. Then I just got it that one-day and I was just like ... I was so so happy. I can do it ever since.

[Paddy, 32]

It takes time (and practice) to accumulate the experience required to translate cognitive understandings into action. Each time the novice sits up on the saddle new opportunities are presented to practice techniques such as rolling on and off the throttle, speeding up and slowing 
down smoothly, making clean gear transitions, and setting up and negotiating turns. New motorcycles, changing weather conditions and untraversed roads present their own challenges. Each obstacle affords the motorcyclist unique opportunities to hone their skills. Paddy's reference to 'the guidelines', re-emphasises the social dimensions of body techniques. Social networks ensure that body technique exists prior to, and after, practical performance. This understanding underscores both their structured nature and structuring effect (Crossley, 2004; 2007b). Through the accumulation of bodily affects Paddy has developed a sense of road craft, an embodied feel that enables him to recognise that the environmental conditions are conducive to performance. This experience is illustrative of Paddy's progression to proficiency. He is no longer fully reliant upon the rules (or guidelines), but rather he is beginning to tune into the particulars of the situation and respond intuitively (Dreyfus, 2014). The risks associated with performing this technique require that the motorcyclist must enter the experience with a degree of abandonment in order to successfully negotiate the technique for the first time. This intense level of focus encompasses a narrowing of the experiential field, as the motorcyclist becomes fully absorbed in negotiating the task at hand. As such, high-speed motorcycling is "a structured and skilful practice which demands self-discipline, [but] it equally demands a degree of 'letting go' - albeit in a structured and contained way" (Crossley, 2004: 57). With enough practice, the body can physically develop "into an organic entity possessed of the postures, dexterities and skills" required to produce the highspeed experience (Shilling, 2008: 145). The feeling of personal transcendence that arises through absorption in the experience often happens in the moments of letting go:

But the only thing that I can remember from that day was the feeling of just overwhelming joy almost. It was like ... Wow! I finally did it! ... You know wheelies aren't my thing ... Yeah, I haven't felt that sensation since, doing anything. It was just one of them buzzes ... But it was just like a great feeling and ever since then I can just do it. Some fellas, like say take Leon for argument's sake, he likes to pop a wheelie every now and again. It's kind of like a moment where you're just like 'Ah, fuck it!' ... The knee-down, well that's my little thing.

[Paddy, 32] 
Paddy underlines the pleasure experienced during (and after) the successful performance of this body technique. Throughout this section, we have come to recognise that skill acquisition, is an essential precursor for those that seek to encounter such pleasures in the high-speed experience. As such, the acquisition of body techniques is an important facet of self-development projects (Crossley, 2005). For Paddy, learning how to get his knee down contributes to his sense of self as a high-speed motorcyclist. The significance of this is greater than simply adding another technique to his corporeal schema. Paddy has also been changed in this moment. Crossley (2005: 13) contends: "By means of these techniques we learn to constitute ourselves for ourselves, practically." In this example, we see that the acquired body technique also serves as a form of bodily capital which distinguishes Paddy as a motorcyclist.

\section{Habituating Bodies to Get in the Zone}

Crossley (2004: 39) conceives of habitus as a fluid and dynamic "lived-through-structure-inprocess, constantly evolving as an effect of the interactions of the agent or group with others and the physical environment." For the phenomenologist, the habitus takes form in interactions between the body-subject and the environment. Paddy illustrates this process while reflecting upon what he learned having nearly crashed while riding in an unfamiliar environment:

It kind of teaches you to keep something in reserve on roads that you're not $100 \%$ familiar with. But with other roads that you know ... roads that you've driven an infinite amount of times ... you know intently, you know to watch out for something here, to be careful here, and little bits like that ... you pick them up and they stay in your head and you'd not so much corner in a certain way but when you're riding that particular road you're in flowing motion. You flow around the place. You know what gear to be in, what speed to be taking it at, you know the conditions of the road. ... Positioning is important as well ... When you're in the zone and you're riding on, you have to have road-positioning right. You'd want to be keeping a buffer of say maybe a foot left or right. You'd have to give yourself good room because if you don't ... sure you know yourself, the price can be pretty big.

[Paddy, 32]

Paddy critically appraises his past performances and "this conscious capacity allows the learner to reflect upon their practices and possibly articulate areas of difficulty or weakness and alter it" 
(Watkins 2008: 120). These moments of self-appraisal were often triggered by difficult experiences. Paddy evokes the interaction between the body-subject and the material environment, illustrating how the accumulation of experience enables him to come to know the environment 'intently'. He describes how his perceptual field has been altered in a manner that enables him to not only perceive, but also to anticipate obstacles on the road. The habitus we see emerging here amounts to "sediments of prior interactions which take shape as habitus in the form of connaissance, trust, background knowledge, expectancies etc.” (Crossley, 2004: 64). High-speed motorcycling necessitates more than just practical knowledge. In a phenomenological sense, it requires a particular embodied intentionality. 'Zoning in' to the task of high-speed motorcycling encompasses a 'tuning out' from everyday attitudes, such that Paddy begins to embody the flow of the motorcycle and the rapidly unfolding environment. This transformation pushes the thought processes of the reflexive mind to the background, as all energies become absorbed in the prereflective task of negotiating the motorcycle at speed; "going with the flow and overriding or relaxing the internalised controls which would usually inhibit such action" (Crossley 2004: 53). This example illustrates how awareness of the body fades away from our experience when the body becomes immersed in purposeful action (Leder, 1990). In order to negotiate the unfolding environment, perceptions of the body must recede to background:

If you're in the zone and you're driving hard. Even on a twisty road if you're not doing big speeds, but you're cornering hard and you're kind of going from corner to corner, dropping gears and going up gears and what not. You don't really have time to think ... If you're on a twisty back road and you see tractor tyres on the road, say now not big clumps of muck but little brown Vs. Then you know that there's machinery working nearby ... You wouldn't be looking in the fields as such but you know that there might be work going on. If you're driving on not going ultra-hard but fairly strong you don't even have time to think of that. I find it very hard to describe.

[Eoin, 28]

When Eoin is in 'the zone', he is fully immersed in the phenomenological experience of motorcycling. The element of speed, and the very real threat that this poses to the body constitutes an intense form of embodiment (Allen-Collinson and Owton, 2015) that distinguishes this 
experience from the majority of everyday consumption experiences. Speed impacts upon the phenomenological experience of lived-time (Tomlinson, 2007), with the window of opportunity for action and reaction reducing as the motorcycle accelerates. In these moments, the techniques that have been inscribed in Eoin's body must do their work. Without thinking, Eoin uses his sensory organs to survey the unfolding environment for danger in the moment. Experience can sharpen perceptual awareness, in this instance enabling Eoin to interpret common road markings as signs of potential danger. This example illustrates the "sensuous rhythm of action and reaction" (Crossley, 2004: 46) that must be acquired to enjoy the high-speed experience. Eoin's recourse to the ineffability of this process indicates that these "are transformations of one's state of being effected by bodily processes beyond one's conscious awareness or control" (Crossley 2004: 54). Indeed, the more accomplished our balance and sensory perception function, the more the body fades from our phenomenological experience of being-in-the world (Leder, 1990: 41-3).

Another thing that drew me to it, my first motorcycle, a Honda NS180 was that because it was so light you could kind of do anything with them. You could wheelie on them. Not because they were powerful but because they were so light ... You could only do it with the power pipe. So what you do is you drive along and the power pipe creates this thing called a powerband ... this was like the turbo that I was talking about. So when you hit that point ... I think it was around 8 or 9 thousand ... so you'd drive slowly up until around 8 or 9 thousand and just when the power band was about to kick in you just tap the clutch, which gave it an extra little boost and then the power pipe kicked in and as you were doing that you bounced the suspension on the bike so you pushed down on the front. So it all had to happen at exactly the same time so ya had to bounce the suspension hit the power band at the right time and touch the clutch. That was the first thing that I wanted to learn how to.

[Leon, 28]

When recalling this bodily technique the chair that Leon is sitting in is transformed into the saddle of the motorcycle. He contorts his body into the position necessitated by this body technique. He raises his hands and wraps them around the imaginary handlebars, crouching forward and ducking his head behind an invisible wind-breaking visor. In this position, he proceeds to perform the techniques described in this narrative, snapping the clutch with two fingers, gripping the throttle and imitating footing the gear lever. His ability to recall how this technique is performed is directly connected to his bodily memory of past performance. In this example, the body is revealed as an 
important source of knowledge that contributes to the high-speed motorcycling habitus. The image of Leon almost bouncing his body to exert his full bodily force through the front suspension, vividly captures the embodied nature of motorcycling techniques.

\section{Discussion}

This paper addresses the means by which consuming bodies come to know how. Attention centres on the acquisition, habituation and diffusion of body techniques among high-speed motorcyclists. Our orientation pivots on the embodiment of action, enabling us to thematise embodiment, while also calling attention to the socio-cultural specificity of particular forms of action. To examine the acquisition of skills, we adopt Crossley's (2004: 38) stance that "body techniques are forms of shared practical reason, pre-representational and pre-reflective forms of collective understanding which complement and interact with collective representations." Indeed, as a concept, body techniques enables us to draw together the social, physical and mindful as constituting elements of an irreducible whole (Crossley, 2007).

\section{Social Aspects of Body Techniques}

Body techniques are constituted by embodied forms of knowledge and understanding that are first social, in the sense that their principles are diffused through social networks (Mauss, 1973). Social networks serve to socialise novices in appropriate and inappropriate ways of doing motorcycling. As novices grasp the shared understanding of what it is to be a motorcyclist, they begin to exist as motorcyclists (Dreyfus, 2014). The present study illuminates the social dynamics of learning, illustrating the prominence of pedagogic mechanisms such as observation, demonstration and instruction in the acquisition, habituation and diffusion of body techniques. The novice's path of development encompasses a mode of teaching which serves to re-calibrate the novice body in line with expert corrections of bad technique and demonstrations of correct form. 
Importantly, the diffusion of body techniques also provides insight into the social dimensions of the corporeal schema. The novice's inability to see mistakes in their own practice, and the subsequent role of peers in highlighting these errors "reveals the limits of the corporeal schema, at the individual level, and the necessity that it be completed by feedback from others" (Crossley, 2007: 89). Observant participation of learning interactions demonstrates that social evaluation of novice performances contributes to the normative diffusion of body techniques. Among groups of motorcyclists, particularised understandings exist in relation to how body techniques should be performed. In the case of high-speed motorcycling, references to 'the racing line' for cornering at speed, and 'the guidelines' for getting your knee down, highlight the group specificity of body techniques (Crossley, 2007b). There is also a historical and cross-cultural variability to body techniques. Those techniques illustrated in this study constitute a particularised form of motorcycling that enables riders to access the gamut of sensations and emotions encompassed in the high-speed experience. These references highlight the social facticity of body techniques.

The social dimensions of the novice's path of development is about more than the transmission of knowledge, or even the acquisition of an implicit structure of engagement. Rather, this form of sociability is about the shared cultivation of increasing levels of skilfulness, the striving for idealised execution, and the disciplining of mistakes (Downey et al. 2015). Through these mechanisms the subject is socially constructed as a motorcycling body, while also becoming connected to the collective body, the motorcycling community (Beauchez, 2018). Each individual's capacity to learn how to become a motorcyclist is invariably tied to the shared knowledge that exists, within social networks, with regards to how motorcycling should be performed (Mauss, 1973; Dreyfus, 2014). 


\section{Physical Aspects of Body Techniques}

Our participants articulated important distinctions between knowing how body techniques should be performed (i.e., a conscious appreciation of body techniques) and actually being able to perform them on a motorcycle in a rapidly unfolding environment. For example, Leon's reflections about learning to 'wheelie' demonstrate that performance does not require a cognitive understanding of the principles of physics. Rather, this understanding is a form of practical know-how. To know body techniques is to put them into action; it is acquired through immersion in the activity (Crossley, 2004). Over time motorcyclists develop a 'feel for it', coming to know in an embodied and pre-reflective sense how techniques should be performed. With repetition skills become refined, eventually being naturalised in the body to the extent that reactions to the environment become largely automatic (Mauss, 1973). Repetition is key to training the body (Mauss, 1973), essentially "training the body through the body", (Samimian-Darash 2013: 59). Once this level of proficiency is reached, the motorcyclist is no longer fully reliant upon the rules (norms) that previously governed their actions. Moving beyond a general level of competence requires motorcyclists to take risks. As proficient motorcyclists the participants become attuned to the particular demands of the situation, and act accordingly. In this respect, we see the formation of a dynamic and fluid habitus as a lived through structure in process. The habitus evolves as an outcome of individual interactions with others and the surrounding environment (Crossley, 2004). The tendency by participants to return to their bodies and its memories in order to articulate the specifics of body techniques provides a powerful illustration of the body's knowledge.

\section{Mindful Aspects of Body Techniques}

The proficient high-speed motorcyclist must be capable of acting in the moment without thinking. Yet throughout the novice's path of development we also witness the motorcyclists' capacities to reflect upon their own practical sense. The self-appraisal processes enacted during training involve periods of focused attention. Through their observations, demonstrations and instructions, we have 
seen that peers are also deeply implicated in the conscious transformation of the novice's bodily capital. As "conscious acts of calibration" such interventions have the potential to reshape bodily capacities and, with further repetition, consciously refined body techniques can once again re-renter the realm of unconscious activity, as habitus (Noble and Watkins, 2003: 536).

Although not fully developed in Mauss's (1973) work, the mindful act of refinement is important because it reminds us of the capacity for conscious reflection in relation to the habitus. This enables us to account for how body techniques transform and evolve. Extending upon the mindful aspects of body techniques, the present study illustrates how the transition from proficiency to mastery demands that motorcyclists learn to interpret and act in accordance with the particulars of a situation. It is in these moments, when masterful motorcyclists leave the rules behind in order to respond, that body techniques undergo transformation and evolution. The technical nature of these innovations can be subjected to mindful reflection, thus enabling articulation and the subsequent diffusion of innovation through social networks. The transformation and evolution of body techniques also relies upon the creative capacitates of the collective to refine and diffuse these techniques in social networks of interaction (Mauss, 1973). Innovations thus become the new norm. World champion riders like Valentino Rossi and Joey Dunlop provide striking examples of how masterful motorcyclists can change the way that motorcycling is performed. From these examples, it is clear that the relationship between consciousness and automaticity is fundamental to the acquisition, performance and evolution of body techniques (Noble and Watkins, 2003). When we talk about what bodies do we must appreciate that body techniques, as modes of practical activity, are "meaningful, purposive, relatively rational etc, and thus mindful" (Crossley, 2007: 81). In this respect, the tripartite conceptualisation of practical activity, encompassed within the concept of body techniques, transcends the difficulties associated with mind-body dualism. 


\section{Conclusions}

In contributing to the embodied turn in consumer research, the present study recognises the embodied nature of experiences (Holbrook and Hirschman, 1982). Such a move necessitates a theoretical and methodological approach capable of attending to the bodily basis of experience. In combination, Mauss (1973) and Crossley (2001; 2004; 2005; 2007) provide a novel means of conceptualising the body as a source of knowledge, while also recognising its significance in relation to the consumption of experience. Our focus on the skilful body enables us to return to a host of experiential work, confident in the understanding that the experiences realised through participation in practical activities such as motorcycling, surfing (Canniford and Shankar, 2012), salsa dancing (Hewer and Hamilton, 2011), free-skiing and paintballing (Woermann and Rokka, 2016) cannot be accessed through the mere act of consumption. Understanding the depth of the practical investment made by our participants is significant because it emphasises the technical nature of these activities. Moreover, it enables us to appreciate that experiences of this nature do not necessarily present themselves easily to unskilled consumers.

Body techniques "put an agent in situation; that is to say, they modify perceptual, affective and cognitive structures" (Crossley, 2007: 90). In contributing to our understanding of embodiment in consumer research, the present study demonstrates the value of recognising perception as an active bodily process that is structured through learning. In unpacking the social, physical and mindful dimensions of skill acquisition, we illuminate the often overlooked, repetitive processes through which shared knowledge becomes embodied. This analytic focus enables us to demonstrate the forces at play in constructing consuming subjects. By way of the habitus, it becomes possible to see how practical activity can sediment to form enduring dispositions that shape how consumers think, act and feel. By acknowledging the tedious and repetitive nature of bodily learning, we reveal the centrality of skill acquisition in accessing consumption experiences. In motorcycling, skill acquisition opens up opportunities for experiencing speed, and all of its intense sensations and 
emotions. But the prospective surfer, salsa dancer or free-skier starts out facing the same predicaments as novice motorcyclists. To become, they must first understand how various body techniques should be performed. This necessitates bodies that are equipped to cope with the practical nature of these activities. They must rehearse and repeat each technique until it is inscribed in the body in an adequate form. To gain proficiency they must reach a point where the activity begins to run through their bodies. To be masterful they must leave the general rules behind in order to interpret and react to the particulars of various situations. The present study contributes to our understanding of the consumer experience by highlighting that skill acquisition is the means through which these worlds and their experiential possibilities can be prised open by consumers. By addressing the processes that facilitate skilled embodiment, and the taken for granted nature of practical activity, we underscore the significance of the moments that occur away from (or prior to) the intensity of extraordinary experience (Carù and Cova, 2003). In the everyday mundane doing there is a becoming. It is this becoming that provides the platform to experience.

The marketplace can play a central role in facilitating the novice's progression to proficiency and mastery. Instructors and interactive social networks of the likes previously conceptualised as brand communities and subcultures of consumption have the capacity to deploy shared understandings of body techniques to help re-calibrate consuming bodies. Recognising the social dynamics at work in 'tuning' motorcycling bodies is particularly important when we consider the emphasis that institutional authorities tend to place upon individual motorcyclists around personal responsibility and individual safety (Murphy and Patterson, 2011). As we illustrate, the motorcycling body is a social construction brought into being largely on the basis of the shared understanding of what it is to be a motorcyclist. It is clear that the best way to effect positive change in the ways that people think about (and perform) motorcycling is through the collective (Martin et al., 2006). Future institutional efforts to improve rider safety must interject at the social level. It is only by changing the collective understanding of appropriate performance in motorcycling that levels of safety will be 
improved. Positive change will in turn influence the ways in which future generations of motorcyclists are brought into being.

\section{References}

Andersson J, Östman L and Öhman M (2015) I am sailing - Towards a transactional analysis of 'body techniques'. Sport, Education and Society 20(6): 722-740.

Allen-Collinson J and Owton H (2015) Intense embodiment: Senses of heat in women's running and boxing. Body \& Society 21(2): 245-268.

Arnold S and Fischer E (1994) Hermeneutics and consumer research. Journal of Consumer Research 21(1): 55-70.

Arnould E and Price L (1993) River magic: Extraordinary experience and the extended service encounter. Journal of Consumer Research 20(1): 24-45.

Atkinson P and Coffey A (2003) Revisiting the relationship between participant observation and interviewing. In Holstein J and Gubrium J (eds.) Inside Interviewing: New Lenses, New Concerns, Thousand Oaks, CA: Sage, pp.415-428.

Beauchez J (2018) 'Never take pity': An average French boxer's ethnobiography. Leisure Studies, DOI: $10.1080 / 02614367.2018 .1429484$

Belk R and Costa J (1998) The mountain man myth: A contemporary consuming fantasy. Journal of Consumer Research 25(3): 218-240.

Bourdieu P (1984) Distinction: A social critique of the judgement of taste, Cambridge, Massachusetts: Harvard University Press.

Canniford R and Shankar A (2012) Purifying practices: How consumers assemble romantic experiences of nature. Journal of Consumer Research 39(5): 1051-1069.

Carman T (2008) Merleau-Ponty. London: Routledge.

Carù A and Cova B (2003) Revisiting consumption experience: A more humble but complete view of the concept. Marketing Theory 3(2): 267-286.

Celsi R, Rose R, and Leigh T (1993) An exploration of high-risk leisure consumption through skydiving. Journal of Consumer Research 20(1), 1-23.

Chamberlayne P and King A (2000) Cultures of Care: Biographies of Carers in Britain and the Two Germanies. Bristol: Policy Press.

Coffey A and Atkinson P. (1996) Making Sense of Qualitative Data: Complementary Research Strategies, London: Sage.

Cronin, J and Hopkinson G (2017) Bodysnatching in the marketplace: Market-focused health activism and compelling narratives of dys-appearance.Marketing Theory, DOI: 1470593117740754. 
Crossley N (2001) The Social Body: Habit, Identity and Desire. London: Sage.

Crossley N (2004) The circuit trainer's habitus: reflexive body techniques and the sociality of the workout. Body \& Society 10(1): 37-69.

Crossley N (2005) Mapping reflexive body techniques: On body modification and maintenance. Body \& Society 11(1): 1-35.

Crossley N (2007) Researching embodiment by way of 'body techniques'. The Sociological Review 55(s1): 80-94.

Dant T (2004) The Driver-car. Theory, Culture \& Society 21(4-5): 61-79.

Delamont S (1992) Fieldwork in Educational Settings: Methods, Pitfalls and Perspectives. London: Falmer.

Downey G, Dalidowicz M and Mason P (2015) Apprenticeship as method: Embodied learning in ethnographic practice. Qualitative Research 15(2): 183-200.

Dreyfus H (2014) Skillful Coping: Essays on the Phenomenology of Everyday Perception and Action. Oxford: Oxford University Press.

Gladwell M (2008) Outliers: The Story of Success. New York: Little, Brown and Co.

Goulding C, Shankar A, Elliott R and Canniford R (2009) The marketplace management of illicit pleasure. Journal of Consumer Research 35(5): 759-771.

Grosz E (1994) Volatile Bodies: Toward a Corporeal Feminism, Bloomington, IN: Indiana University Press.

Haigh $\mathbf{J}$ and Crowther $\mathrm{G}$ (2005) Interpreting motorcycling through its embodiment in life story narratives. Journal of Marketing Management 21(5-6): 555-572.

Halkier B and Jensen I (2011) Methodological challenges in using practice theory in consumption research: Examples from a study on handling nutritional contestations of food consumption. Journal of Consumer Culture 11(1): 101-123.

Hewer P and Hamilton K (2010) On emotions and salsa: Some thoughts on dancing to rethink consumers. Journal of Consumer Behaviour 9(2): 113-125.

Holbrook M (2001) Times Square, Disneyphobia, HegeMickey, the Ricky Principle, and the downside of the entertainment economy. Marketing Theory 1(2): 139-163.

Holbrook M and Hirschman E (1982) The experiential aspects of consumption: Consumer fantasies, feelings, and fun. Journal of Consumer Research 9(2): 132-140.

Jantzen C, Fitchett J, Østergaard P and Vetner M (2012) Just for fun? The emotional regime of experiential consumption. Marketing Theory 12(2): 137-154.

Joy A and Sherry J (2003) Speaking of art as embodied imagination: A multisensory approach to understanding aesthetic experience. Journal of Consumer Research 30(2): 259-282.

Kane M and Zink R (2004) Package adventure tours: Markers in serious leisure careers. Leisure Studies 23(4): 329-345. 
Kozinets R (2002) Can consumers escape the market? Emancipatory illuminations from burning man. Journal of Consumer Research 29(1): 20-38.

Lanier C and Rader C (2015) Consumption experience: An expanded view. Marketing Theory 15(4): 487-508.

Larsen J (2014) (Auto)Ethnography and cycling. International Journal of Social Research Methodology 17(1): 59-71.

Leder D (1990) The Absent Body. Chicago: University of Chicago Press.

Macnamara B, Hambrick D and Oswald F (2014) Deliberate practice and performance in music, games, sports, education, and professions: A meta-analysis. Psychological Science 25(8): 16081618.

Martin D, Schouten J and McAlexander J (2006) Claiming the throttle: Multiple femininities in a hyper-masculine subculture. Consumption Markets \& Culture 9(3): 171-205.

Mauss M (1973) Techniques of the body. Economy and Society 2(1): 70-88.

Merleau-Ponty M (1962) Phenomenology of Perception. London: Routledge.

Morris B (2004) What we talk about when we talk about 'walking in the city'. Cultural Studies 18(5): 675-697.

Murphy S and Patterson M (2011) Motorcycling edgework: A practice theory perspective. Journal of Marketing Management 27(13-14): 1322-1340.

Noble G and Watkins M (2003) So, how did Bourdieu learn to play tennis? Habitus, consciousness and habituation. Cultural Studies 17(3-4): 520-539.

Ourahmoune N (2016) Narrativity, temporality, and consumer-identity transformation through tourism. Journal of Business Research 69(1): 255-263.

Phoenix A and Brannen J (2014) Researching family practices in everyday life: Methodological reflections from two studies. International Journal of Social Research Methodology 17(1): 11-26.

Rosa H (2010) Full speed burnout? From the pleasures of the motorcycle to the bleakness of the treadmill: the dual face of social acceleration. International Journal of Motorcycle Studies 6(1).

Samimian-Darash L (2013) Rebuilding the body through violence and control. Ethnography 14(1): 46-63.

Schouten J and McAlexander J (1995) Subcultures of consumption: An ethnography of the new bikers. Journal of Consumer Research 22(1): 43-61.

Scott R, Cayla J and Cova B (2017) Selling Pain to the Saturated Self. Journal of Consumer Research 44(1): 22-43.

Seregina A and Weijo H (2016) Play at any cost: How Cosplayers produce and sustain their ludic communal consumption experiences. Journal of Consumer Research 44(1): 139-159.

Spencer D (2009) Habit(us), body techniques and body callusing: An ethnography of mixed martial arts. Body \& Society 15(4): 119-143. 
Spencer D (2014) Sensing violence: An ethnography of mixed martial arts. Ethnography 15(2): 232-254.

Sudnow D (1993) The Ways of the Mind: The Organisation of Improvised Conduct. Massachusetts: Massachusetts Institute of Technology.

Thompson C (1997) Interpreting consumers: a hermeneutical framework for deriving marketing insights from the texts of consumers' consumption stories. Journal of Marketing Research 3(4): 438-455.

Thompson C, Locander W and Pollio H (1989) Putting consumer experience back into consumer research: The philosophy and method of existential-phenomenology. Journal of Consumer Research 16(2): 133-146.

Thompson $\mathrm{C}$ and Üstüner $\mathrm{T}$ (2015) Women skating on the edge: Marketplace performances as ideological edgework. Journal of Consumer Research 42(2), 235-265.

Tomlinson J (2007) The Culture of Speed: The Coming of Immediacy. London: Sage.

Turner T (1994) Bodies and anti-bodies: Flesh and fetish in contemporary social theory. In Csordas T (ed.) Embodiment and Experience: The Existential Ground of Culture and Self, Cambridge: Cambridge University Press, pp.27-47.

Valtonen A and Närvänen E (2015) Gendered reading of the body in the bed. Journal of Marketing Management 31(15-16): 1583-1601.

Wacquant L (2004) Body and Soul. Oxford: Oxford University Press.

Wacquant L (1995a) Pugs at work: Bodily capital and bodily labour among professional boxers. Body \& Society 1(1): 65-93.

Wacquant L (1995b) Review article: Why men desire muscles. Body \& Society 1(1): 163-179.

Watkins M (2008) Teaching bodies/learning desire: rethinking the role of desire in the pedagogic process. Pedagogy, Culture \& Society 16(2): 113-124.

Wengraf T (2001) Qualitative Research Interviewing: Biographic Narrative and Semi-structured Methods. London: Sage.

Woermann N and Rokka J (2015) Timeflow: How consumption practices shape consumers' temporal experiences. Journal of Consumer Research 41(6): 1486-1508.

Woodward M and Holbrook M (2013) Dialogue on some concepts, definitions and issues pertaining to 'consumption experiences'. Marketing Theory 13(3): 323-344.

Table $1 \quad$ Participant Profiles

\begin{tabular}{|l|l|l|}
\hline Leon & 29 & Graphic Designer \\
\hline Michael & 29 & Machine Operator \\
\hline
\end{tabular}




\begin{tabular}{|l|l|l|}
\hline John & 31 & Builder \\
\hline Eoin & 28 & Engineer \\
\hline Paddy & 32 & Tool Maker \\
\hline Jimmy & 28 & Carpenter \\
\hline Tom & 30 & Electrician \\
\hline Kevin & 45 & Motorcycle Instructor \\
\hline
\end{tabular}

